УДК 001.57; 658.818; 681.3

DOI 10.18413/2411-3808-2019-46-1-84-91

МЕТОД КРОСТОНА В ПРОГНОЗИРОВАНИИ ТОВАРНЫХ ЗАПАСОВ

\title{
CROSTON METHOD FOR FORECASTING THE EXAMPLE OF SPARE PARTS OF MEDICAL EQUIPMENT
}

\author{
О.А. Мельникова ${ }^{1}$, М.В. Крашенинников ${ }^{2}$ \\ O.A. Melnikova ${ }^{1}$, M.V. Krasheninnikov ${ }^{2}$ \\ ${ }^{1} \mathrm{OOO}$ «Радиоэлектронные системы», \\ 620018 , г. Екатеринбург, ул. Июльская, 41 \\ ${ }^{2}$ ФГБОУ ВО «Уральский государственный медицинский университет» Минздрава России, \\ Россия, 620028, г. Екатеринбург, ул. Репина, 3 \\ ${ }^{1}$ Development Radioelectronic Systems LLC, \\ 620018 Ekaterinburg, 41 July st. \\ ${ }^{2}$ «Ural State Medical University» of the Ministry of Health of Russia, \\ Russia, 620028, Yekaterinburg, 3 Repin st. \\ E-mail: newfarmacia@mail.ru
}

\begin{abstract}
Аннотация. В данной работе рассматривается проблема прогнозирования запасных частей для медицинского оборудования на основе анализа рынка медицинской техники. Проведённый анализ показывает, что закупка происходит за счёт различных государственных субсидий, однако не обеспечивает должный уровень качества медицинской техники. В связи с этим возникает необходимость в модернизации имеющегося медицинского оборудования. В статье рассматривается метод прогнозирования типовых деталей для медицинской техники, нуждающейся в ремонте и технических работах (на примере типовой медицинской организации) с помощью оригинального метода Кростона, прогнозирующего потребность в деталях, спрос на которые осуществляется прерывисто. В статье приведены математические расчёты прогноза поломки запасных частей, приведен алгоритм построения прогнозного тренда по методу Кростона в формате Excel. Результаты прогноза запасных частей на медицинскую технику, структурированные в таблице, показали, что средние значения, определённые по методу Кростона, являются наиболее реальными для планирования складских запасов.
\end{abstract}

Abstract. This article deals with the problem of predicting spare parts for medical equipment based on an analysis of the medical equipment market. The analysis shows that the purchase is due to various government subsidies. However, it does not ensure the proper level of quality of medical equipment. In this regard, there is a need to modernize the existing medical equipment. The article discusses a method for predicting typical parts for medical equipment that needs repair and technical work (using a typical medical organization as an example) using the original Croston method, which predicts the need for parts that are in demand intermittently. The article presents mathematical calculations of the prediction of failure of spare parts, an algorithm for constructing a forecast trend using the Croston method in Excel format. The results of the forecast of spare parts for medical equipment structured in the table showed that the average values determined by the Croston method are the most realistic for planning inventory.

Ключевые слова: прогнозирование, метод Кростона, планирование запасов, медицинская техника, запасные части.

Keywords: forecasting, Croston method, inventory planning, medical equipment, spare parts. 


\section{Введение}

Изменение законодательства в области закупок товаров народного потребления, а именно введение Федерального закона от 5 апреля 2013 г. № 44-Ф3 привело к уже сложившейся перестройке процедуры закупки. Введенные изменения затронули все отрасли медицины и фармации и обусловили необходимость поиска новых путей в области нормирования и прогнозирования потребностей в медицинских товарах. Монетаристская теория, связывающая инфляцию и состояние денежного обращения, не дала каких-либо результатов в практическом применении закона о закупках товаров. В сложном положении оказалась область медицинской техники, где имеется возможность устанавливать цены на разные товарные марки и товарные знаки. В связи с этим производители техники могут самостоятельно устанавливать отпускную цену на медицинское оборудование, и оно может различаться в разы. Кроме того, низкая платежеспособность медицинских организаций на дорогостоящую медицинскую технику приводит к ухудшению материальной базы больницы. Между тем качественное оказание медицинской помощи невозможно без достаточного уровня медицинского оборудования. Закупка медицинской техники за счёт различных государственных субсидий не может обеспечивать того уровня качественный медицинской техники, в результате этого каждая больница ежегодно должна затрачивать денежные средства на модернизацию уже имеющейся медицинской техники.

Практическое решение проблемы модернизации медицинской техники требует решения ряда сложных методологических проблем, среди которых важнейшей является проблема, связанная с прогнозированием. Данная проблема состоит в том, что части медицинского оборудования функционируют как определенные составные части в крупной сложной системе, поэтому их прогноз представляет достаточно сложную задачу. В связи с этим целью данной работы было составление прогнозов с помощью метода Кростона.

На первом этапе работы большой интерес представлял анализ типовых медицинских организаций на предмет закупаемой медицинской техники и выявление оборудования и запасных частей, которые подлежат закупке наиболее часто. Результаты анализа представлены в таблице 1 [Официальный сайт гос. закупок].

Таблица 1

Table 1

Количество приобретаемой и ремонтируемой медицинской техники 2016 г. -1 полугодие 2019 г. Number of purchased and repaired medical equipment 2016 - 1st half of 2019

\begin{tabular}{|l|c|c|c|}
\hline \multicolumn{1}{|c|}{ Наименование медицинской организации } & $\begin{array}{c}\text { Количество } \\
\text { закупленной } \\
\text { медицинской } \\
\text { техники } \\
\text { (ОКПД 2 } \\
32.50)\end{array}$ & $\begin{array}{c}\text { Количество } \\
\text { वукционов по } \\
\text { ремонту } \\
\text { медицинской } \\
\text { техники (ОКПД } \\
233.13 .12)\end{array}$ & $\begin{array}{c}\text { Количество } \\
\text { собственных } \\
\text { средств } \\
\text { медицинской } \\
\text { организации }\end{array}$ \\
\hline 1 & 2 & 3 & 4 \\
\hline $\begin{array}{l}\text { Государственно бюджетное учреждение здравоохра- } \\
\text { нения «Клинический онкологический диспансер № 1» } \\
\text { Министерства здравоохранения Краснодарского края }\end{array}$ & - & 1 & 100 \\
\hline $\begin{array}{l}\text { Бюджетное учреждение здравоохранения Вологод- } \\
\text { ской области «Вологодская городская больница № 1» }\end{array}$ & 2 & 1 & 100 \\
\hline $\begin{array}{l}\text { Государственное бюджетное учреждение «Карга- } \\
\text { польская центральная районная больница» }\end{array}$ & - & 1 & 100 \\
\hline $\begin{array}{l}\text { Государственное бюджетное учреждение здраво- } \\
\text { охранения Ставропольского края «Александровская } \\
\text { районная больница» }\end{array}$ & - & 1 & 100 \\
\hline $\begin{array}{l}\text { Муниципальной бюджетное учреждение здраво- } \\
\text { охранения города Армавира «Перинатальный центр» }\end{array}$ & - & 1 & 100 \\
\hline
\end{tabular}


Окончание табл. 1

\begin{tabular}{|l|l|c|c|}
\hline \multicolumn{1}{|c|}{1} & 2 & 3 & 4 \\
\hline $\begin{array}{l}\text { Государственное бюджетное учреждение здраво- } \\
\text { охранения «Городская клиническая больница № 1» } \\
\text { города Краснодара Министерства здравоохранения } \\
\text { Краснодарского края }\end{array}$ & - & 1 & \\
\hline
\end{tabular}

Из таблицы видно, что медицинские организации приобретают медицинскую технику и медицинское оборудование очень редко и за бюджетные средства. В основном они предпочитают ремонтировать медицинскую технику и проводить её техническое обслуживание. Анализ технической документации к аукциону на анализ на оказание услуг по ремонту медицинской техники замены запасных частей (Государственное бюджетное учреждение «Каргапольская центральная районная больница») показал, что в медицинской организации имеется различная медицинская техника разных годов выпуска.

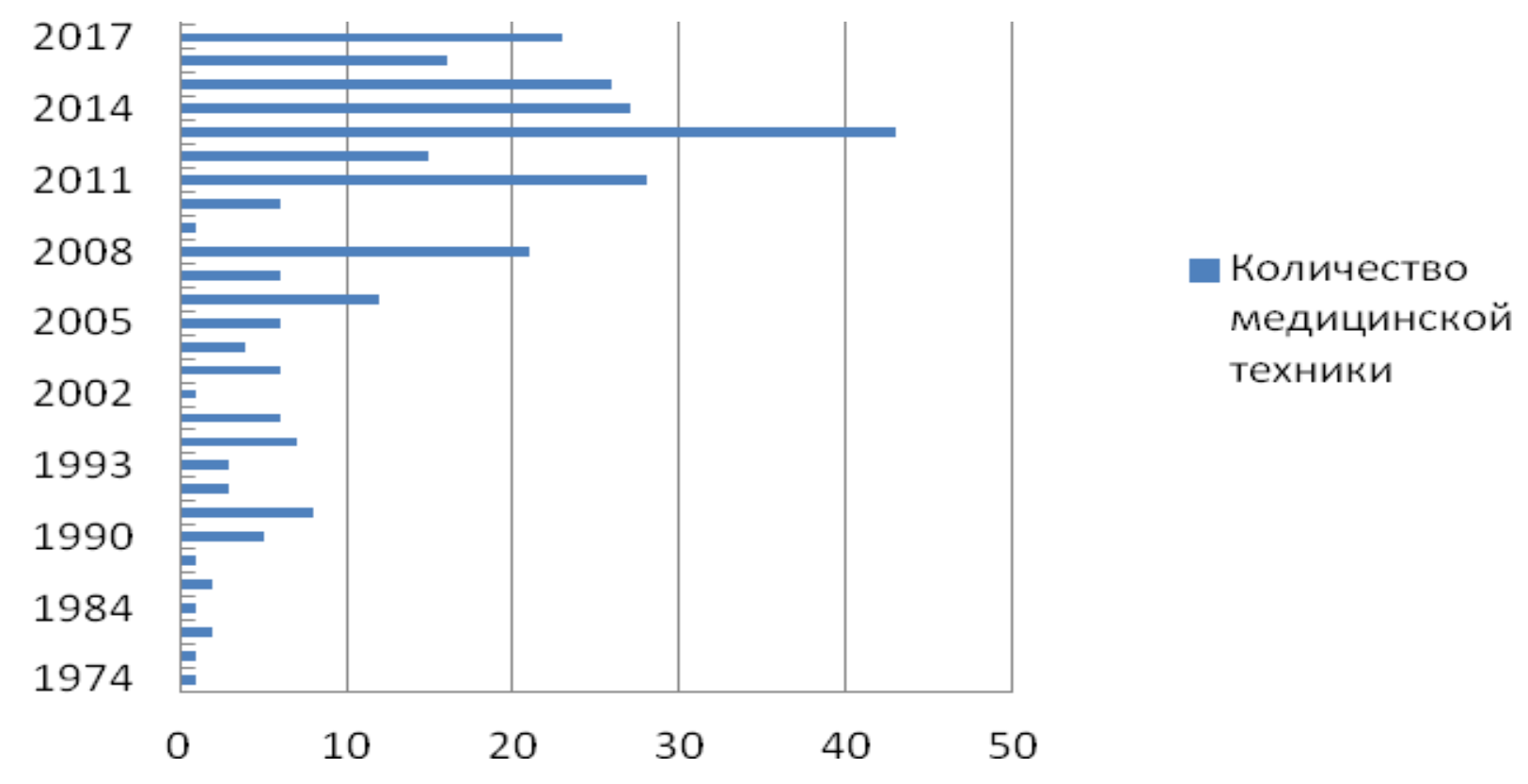

Рис. 1. Количество медицинской техники, требующее проведения ремонтно-технических работ

Fig. 1. The amount of medical equipment, which requires conducting maintenance

Из рисунка видно, что увеличение потребности в медицинской технике требует достаточного количества запасных частей и квалификации работников. В рыночной экономике для медицинской организации не выгодно лично заниматься обслуживанием и ремонтом медицинской техники, выгодным является передача этой функции специализированным организациям. Такой выбор обусловлен тем, что для ремонта медицинской техники в организации должен быть предусмотрен специальный отдел, который требует определенного вложения затрат и является косвенной услугой для медицинской организации. Существует несколько вариантов организации ремонта и поверки медицинского оборудования:

1. Производитель медицинской техники имеет по всей стране множество филиалов, которые занимаются ремонтом производимого фирмой оборудования.

2. Завод-производитель может иметь центральное представительство и осуществлять сервисные функции с их помощью.

3. Завод-производитель может обеспечивать непосредственно заказчиков запасными частями путем рассылки их по тем больницам, которыми эта техника была куплена. 
4. Завод-производитель заключает договор с независимой организацией, ремонтирующий медицинскую технику, которая берет на себя обязательство по ремонту и гарантийному обслуживанию.

Однако, несмотря на выбранный способ, осуществление ремонта и замены запасных частей важным является определение их номенклатуры и количества. Запасные части для ремонта медицинской техники необходимо уметь рассчитать по следующим показателям:

1. По показателям, связанным с пригодностью к ремонту. Деталь может быть не ремонтируемой, а может подлежать ремонту.

2. По виду ремонта (простой, комплексный).

3. По виду прогнозирования необходимых запасных частей (аналитический, регрессионный анализ и другие).

В настоящем исследовании мы осуществим прогнозирование по Методу Кростона. Необходимо отметить, что обычные методики прогнозирования подчиняются таким понятиям, как тренд или сезонность. В случае, когда нельзя построить тренд или сезонность, то есть существуют периоды поломки запчастей, а затем период длительной работы, то действуют другие алгоритмы предсказания замены. Кростон предположил [Croston 1972, Rao 1973, Croston, 1996], что все замены статистически независимы и случилась ли поломка запчасти или нет, это всё равно подчиняется закону Бернулли, то есть вероятностью р события произойдет, а с вероятностью 1-р- нет.

Оригинальный метод Кростона прогнозирует две независимые величины: период между поломками детали Pt и собственно величину (объём потребности) на замену сломанных деталей Zt.

Если на период работы поломки деталей не возникает, показатели Zt и Pt, соответственно, остаются неизменными. Если поломка, ведущая к замене запчасти, возникает так,

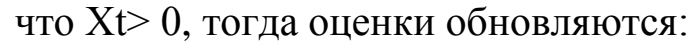

$$
\begin{gathered}
Z_{(t)}=X(t)+(1-\alpha) Z_{t-1} \\
n_{t}=\beta n_{t}+(1-\beta) n_{t-1}
\end{gathered}
$$

где

$\mathrm{Xt}$ - фактический спрос на замену детали в момент времени $\mathrm{t}$;

$\mathrm{Zt}$ - объём потребности в конкретное время $\mathrm{t}$;

$\mathrm{n}_{\mathrm{t}}-$ номер периода после последней замены в момент времени $\mathrm{t}$;

$(\alpha)$ и $\beta$ постоянная, сглаживания от нуля до единицы. В нашем случае возьмём (a) $=0,3$, а $\beta=0,2$ [Johnston, Boylan and Shale, 2003].

Следовательно, прогноз поломки запчасти на момент времени t будет равен [Syntetos, Boylan, 2001, Syntetos, Boylan and Croston, 2005]:

$$
\mathrm{X}_{(t+1)}=\frac{z_{t}}{n_{t}}
$$

Проведём расчёт по методу Кростона [Syntetos and Boylan, 2010] по следующим данным за 2 года, используя данные о запросе на следующие виды запасных деталей. Для этого воспользуемся данными на запасные части, представленными на рисунках 2, 3, 4, полученными с помощью [Johnston and Boylan 2010, Shale, Boylan, Johnston, 2006]. 


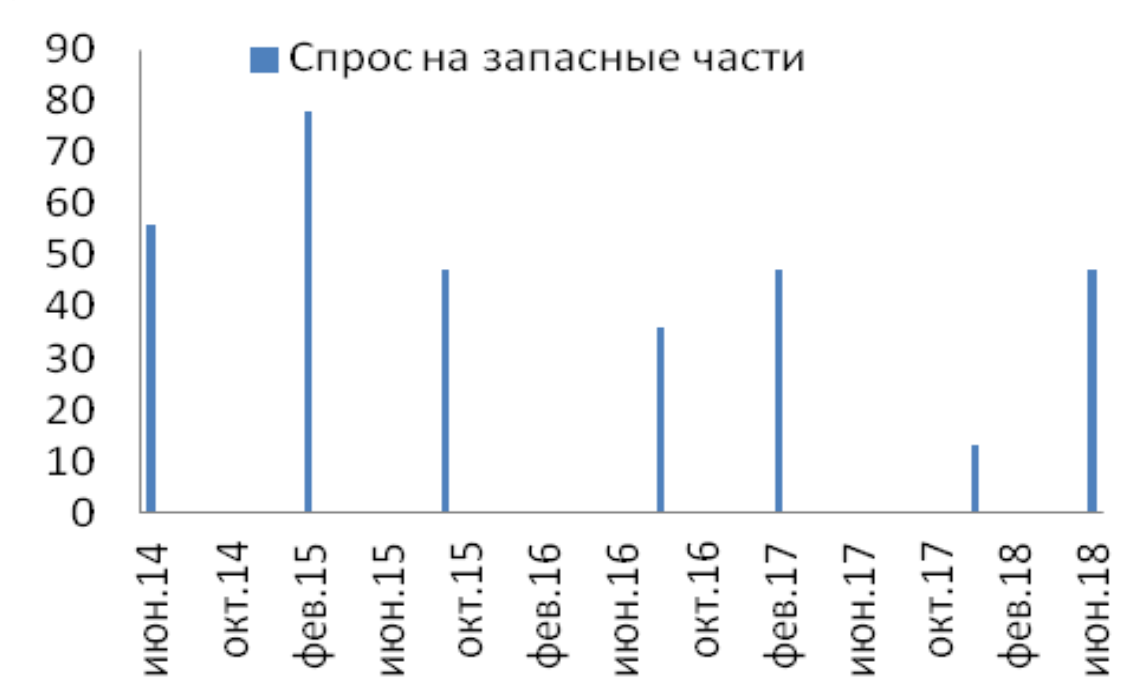

Рис. 2. Данные о замене антибактериального фильтра (аппарат для искусственной вентиляции легких) Fig. 2. Data on the replacement of the antibacterial filter (apparatus for mechanical ventilation)

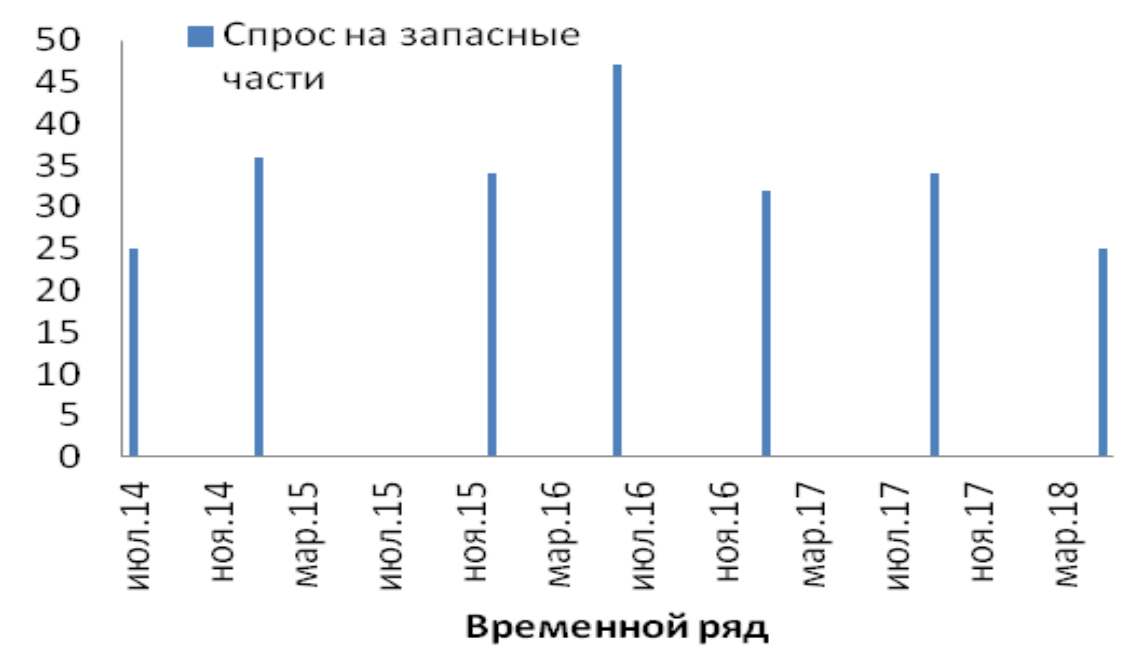

Рис. 3. Данные о замене запасной части датчик кислорода (аппарат для искусственной вентиляции легких)

Fig. 3. Data about spare replacement oxygen sensor (apparatus for artificial ventilation of lungs)

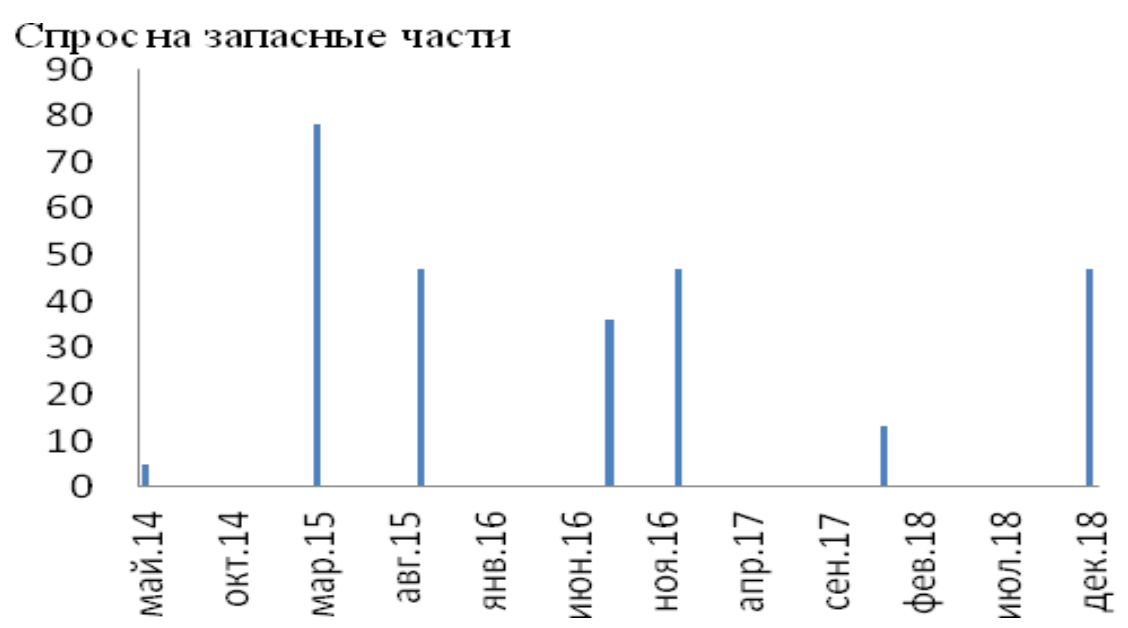

Рис. 4. Данные о замене прокладки парогенератора (Стерилизатор паровой «ГК-100-3»)

Fig. 4. Information on the replacement of the gaskets of the steam generator (Steam sterilizer «GK-100-3») 
Графические данные, представленные на рисунках 2-4, структурированы в таблицу 2. По формуле 3 определим степень прерывистости.

Таблица 2

Table 2

Данные о замене запасных частей на медицинское оборудование

Data on replacement of spare parts with medical equipment

\begin{tabular}{|l|c|c|c|c|}
\hline $\begin{array}{c}\text { Наименование запасной } \\
\text { части }\end{array}$ & $\begin{array}{c}\text { Количество } \\
\text { запасных } \\
\text { частей }\left(\mathrm{Z}_{\mathrm{t}}\right)\end{array}$ & $\begin{array}{c}\text { Время, когда } \\
\text { запасная часть } \\
\text { не требовалась (года) }\left(\mathrm{n}_{\mathrm{t}}\right)\end{array}$ & $\begin{array}{c}\text { Отношение } \\
(2 / 3) \\
\left(\mathrm{X}_{\mathrm{t}}\right)\end{array}$ & $\begin{array}{c}\text { Степень } \\
\text { прерывистости }\end{array}$ \\
\hline $\begin{array}{l}\text { Антибактериальный } \\
\text { фильтр (аппарат для } \\
\text { искусственной } \\
\text { вентиляции легких) }\end{array}$ & 24 & 3 & 19 & 5 \\
\hline $\begin{array}{l}\text { Датчик кислорода (аппарат } \\
\text { для искусстенной } \\
\text { вентиляции легких) }\end{array}$ & 233 & 62 & 24 & $\begin{array}{c}\text { Низкая } \\
\text { прерывистость }\end{array}$ \\
\hline $\begin{array}{l}\text { Прокладка парогенератора } \\
\text { (Стерилизатор паровой } \\
\text { «ГК-100-3») }\end{array}$ & 273 & 65 & 24 & $\begin{array}{c}\text { Вредяя } \\
\text { прерысокая }\end{array}$ \\
\hline
\end{tabular}

Результаты данной таблицы показывают нам потребность в запасной части в момент времени t. Однако нас интересует прогнозный тренд. Для этого рассчитаем потребность в запасных частях на примере антибактериального фильтра (аппарат для искусственной вентиляции легких) по методу Кростона [Teunter, Syntetos, Babai, 2011]. Первичные данные из рисунка 2 переведём в формат Excel и построим таблицу.

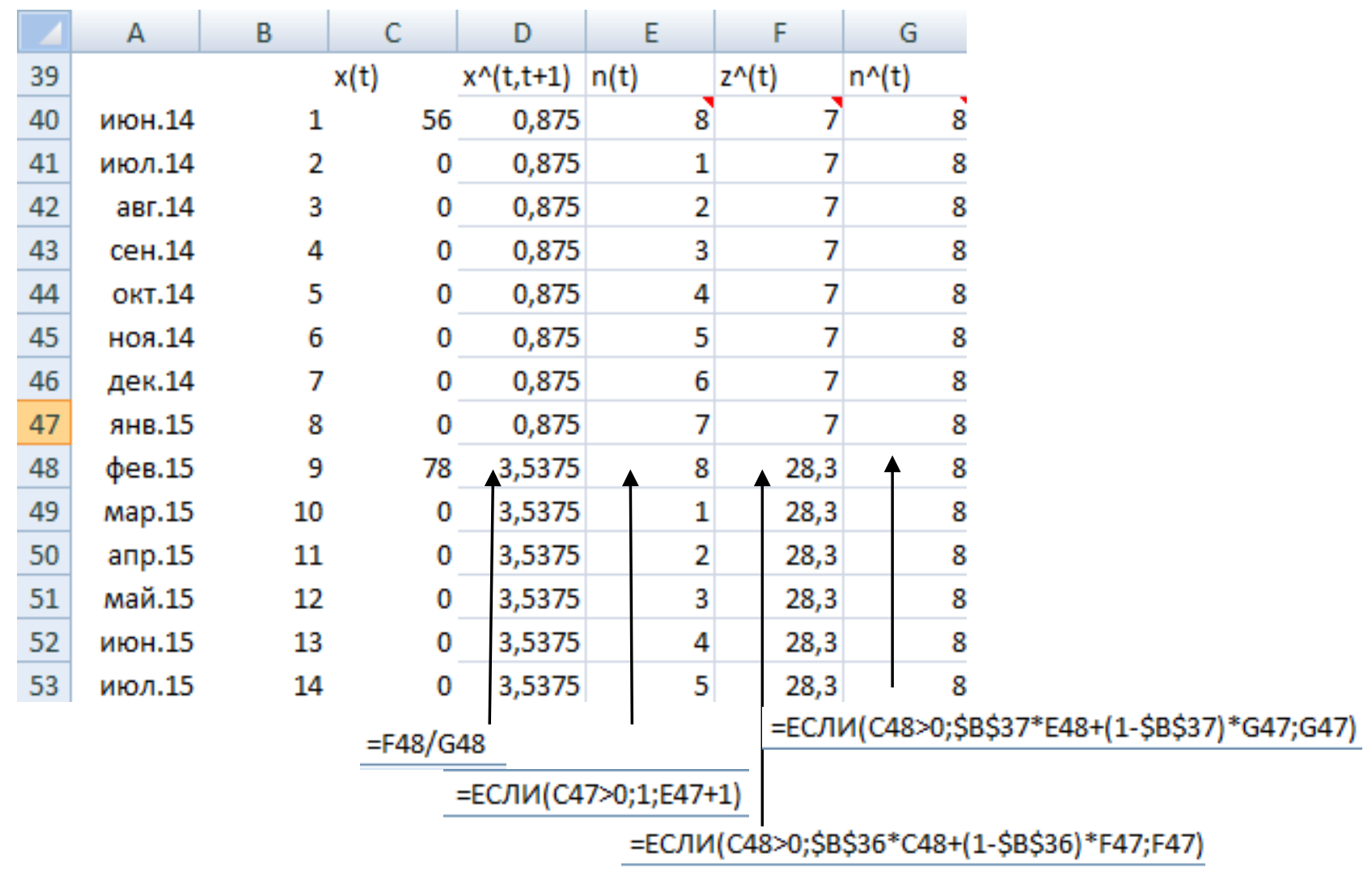

Рис. 5. Фрагмент данных для расчёта методом Кростона и методика расчёта

Fig. 5. The fragment data for the calculation method and the Croston method of calculation 
На основании данных, представленных на рисунке 5, был построен прогнозный тренд в запасных частях для антибактериального фильтра.

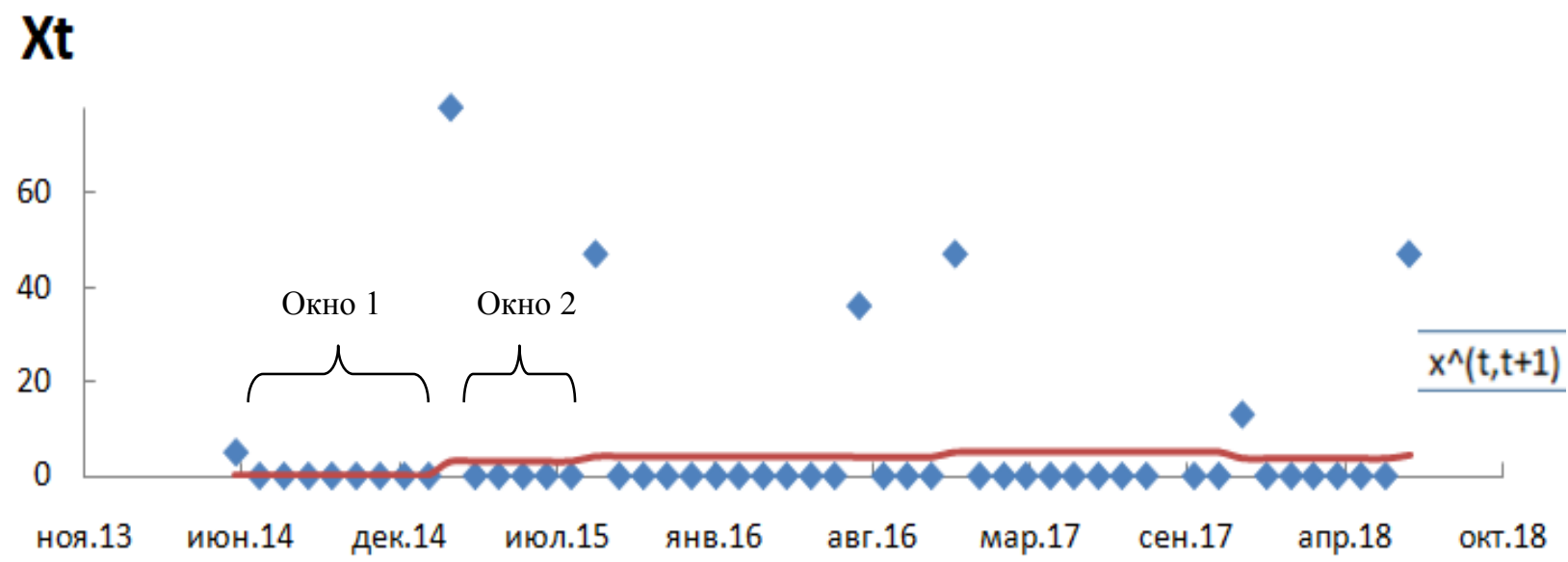

Рис. 6. Прогнозирование спроса по методу Кростона на примере антибактериальных фильтров Fig. 6. Demand forecasting by Croston method on the example of antibacterial filters

Видно, что в прогнозе запасных частей существуют определённые «окна». Структурирование данных из рисунка 6 , а также расчёт дополнительных данных для датчика кислорода и прокладок парогенератора представлены в таблице 3.

Таблица 3

Table 3

Суммарная таблица прогнозирования спроса в запасных частях на медицинскую технику по методу Кростона

Summary table of demand forecasting in spare parts for medical equipment by Croston method

\begin{tabular}{|l|c|c|c|c|c|c|c|c|}
\hline $\begin{array}{l}\text { Наименование запасной } \\
\text { части }\end{array}$ & Окно 1 & Окно 2 & Окно 3 & Окно 4 & Окно 5 & Окно 6 & Окно 7 & $\begin{array}{c}\text { Среднее } \\
\text { значение }\end{array}$ \\
\hline \multicolumn{1}{|c|}{1} & 2 & 3 & 4 & 5 & 6 & 7 & 8 & 9 \\
\hline $\begin{array}{l}\text { Антибактериальный } \\
\text { фильтр (аппарат для } \\
\begin{array}{l}\text { искусственной } \\
\text { вентиляции легких) }\end{array}\end{array}$ & 1 & 4 & 5 & 4 & 5 & 4 & 5 & 4 \\
\hline $\begin{array}{l}\text { Датчик кислорода } \\
\text { (аппарат для искусственной } \\
\text { вентиляции легких) }\end{array}$ & 1 & 2 & 3 & 4 & 5 & 5 & 5 & 3,5 \\
\hline $\begin{array}{l}\text { Прокладка парогенератора } \\
\text { (Стерилизатор паровой) }\end{array}$ & 1 & 2 & 3 & 4 & 5 & 5 & 5 & 3,5 \\
\hline
\end{tabular}

Таким образом, анализ показал, что прогнозирование спроса в запасных частях на медицинскую технику по методу Кростона является наиболее реальным для планирования и содержания складских запасов.

\section{Заключение}

В работе представлена методика прогнозирования на основе метода Кростона. Данная методика позволяет спрогнозировать потребность в запасных частях медицинскому оборудованию. На современном этапе развития медицины методики прогнозирования будут постепенно развиваться и трансформироваться в область практической деятельности. В связи с этим предлагаемый в работе подход, как надеются авторы, будет востребован. 


\section{Список литературы \\ References}

1. Федеральный закон от 5 апреля 2013 г. № 44-Ф3 «О контрактной системе в сфере закупок товаров, работ, услуг для обеспечения государственных и муниципальных нужд» (с изменениями и дополнениями).

Federal law № 44-FZ of 5 April 2013 «On the contract system for the procurement of goods, works and services for state and municipal needs» (as amended) (in Russian).

2. Официальный сайт единой информационной системы в сфере закупок /http://www.zakupki.gov.ru/epz/main/public/home.html.

Official website of the unified information system in the field of procurement /http://www.zakupki.gov.ru/epz/main/public/home.html (in Russian).

3. Bartezzaghi E. and Kalchschmidt M. The impact of aggregation level on lumpy demand management, N. Altay and L.A. Litteral (eds.), Service Parts Management, 2011, pp. 89-104.

4. Croston J.D. Forecasting and stock control for intermittent demands, Operational Research Quarterly, vol. 23, № 3, pp.289-303, 1972.

5. Croston J.D. Croston's method comment, International Journal of Forecasting, vol. 12, № 2, pp. 297-298, 1996.

6. Johnston F.R. and Boylan J.E. «Forecasting intermittent demand: A comparative evaluation of Wallstrom P. and Segerstedt A.», «Evaluation of forecasting error measurements and techniques for intermittent demand», International Journal of Production Economics, vol. 128, № 2, pp. 625-636, 2010.

7. Johnston F.R, Boylan J.E. and Shale E.A. «An examination of the size of orders from customers, their characterization and the implications for inventory control of slow moving items», Journal of the Operational Research Society, vol. 54, № 8, pp. 833-837, 2003.

8. Syntetos A.A., Boylan J.E., On the bias of intermittent demand estimates. Int. J. Prod. Econ. 71(May (1-3)), 457-466, 2001.

9. Syntetos A.A, Boylan J.E. and Croston J.D., «On the categorization of demand patterns», Journal of the Operational Research Society, vol. 56, № 5, pp. 495-503, 2005.

10. Syntetos A.A. and Boylan J.E. «On the variance of intermittent demand estimates», International Journal of Production Economics, vol. 128, № 2, pp. 546-555, 2010.

11. Shale E.A., Boylan J.E., Johnston F.R., Forecasting for intermittent demand: the estimation of an unbiased average. J. Oper. Res. Soc. 57, 588-592. 2006.

12. Teunter R.H., Syntetos A.A., Babai M.Z., Intermittentdemand: linking forecasting to inventory obsolescence. Eur. J. Oper. Res. 214(3), 606-615. 2011.

13. Rao A.V., «A comment on 'Forecasting and stock control for intermittent demands», Operational Research Quarterly, vol. 24, № 4, pp. 639-640, 1973.

14. Willemain T.R., Smart C.N., Shocker J.H. and De Sautels P.A., «Forecasting intermittent demand: A comparative evaluation of Croston's method», International Journal of Forecasting, vol. 10, № 4, pp. 529-538, 1994. 